\title{
Seismic Anisotropy in the Northern Sumatra Region from Shear Wave Splitting
}

\author{
Arya Dwi Candra ${ }^{1 *}$, Bagus Jaya Santosa ${ }^{1}$ \\ ${ }^{I}$ Physics Department, Faculty of Mathematics and Natural Sciences, Institut Teknologi Sepuluh Nopember (ITS), \\ Jl. Arief Rahman Hakim, Surabaya 60111, Indonesia
}

Received: 23 June 2015, Revised: 5 Aughust 2015, Accepted: 21 December 2015

\begin{abstract}
The northern Sumatra consists of several tectonic segments, such as subduction zone, the Sumatra and Mentawai faults. An analysis that can be used to identify the tectonic segments, located beneath the northern Sumatra, is shear wavesplitting. The purpose of the analysis of shear-wave splitting is to monitor the anisotropic characteristics of the structure of the earth layers located beneath the northern Sumatra. The monitoring data were collected from 4 BMKG stations with the magnitude was more than $6.3 \mathrm{Mw}$ and the the range of the epicentral distance was about $85^{\circ}-140^{\circ}$. The data analysis was conducted by using Splitlab program based on rotation-correlation method. The result of the shear-wave splitting analysis shows that there are two anisotropic layers. The delay time found in the first layer is about $0,5-0,9 \mathrm{~s}$, which is assumed that it occurs due to the Sumatran fault. Meanwhile, the delay time found in the second layer is about $1,4-1,8 \mathrm{~s}$, which is assumed that it occurs due to the subduction plate movement on the upper mantle layer. The results of TPTI, TSI and TRSI stations has shown congruence, that is the polarization direction is parallel to the Sumatra fault on the upper layer and the polarization direction is perpendicular to the Sumatra fault on the lower layer. The PSI station shows the polarization direction is different from the other stations, in which they show the polarization direction is perpendicular to the Sumatra fault on the upper layer and the polarization direction is parallel to the Sumatra fault on the lower layer. The difference of the data processing in the PSI station, we assume, is caused by the presence of a complex layer beneath Toba caldera.
\end{abstract}

Keywords: Shear-wave splitting, Seismic anisotropic, Splitlab, the northern Sumatra, Toba caldera.

\section{INTRODUCTION}

Sumatra island is located in a subduction area between two big plates in the world, they are IndoAustralia plate in the south and Eurasia plate in the north. The subduction of the two plates cause Sumatra island, especially the northern Sumatra, to become one of the places in the world that has the most active seismic activities. In general, seismic analyses assume the earth layers have isotropic characteristic, yet most of the rocks making up the earth layers have anisotropic characteristic. This is very important for researchers, in particular seismologists, because it can help them to identify anisotropic characteristic found on the earth layers. One of the geophysical methods that can used to

\footnotetext{
Corresponding author.

E-mail address: arya13@mhs.physics.its.ac.id
}

analyse anisotropic characteristic is shear-wave splitting method.

Many seismological research have already applied the shear-wave splitting analyses to detect anisotropic structure inside the earth ([1]-[4]). Shear-wave splitting occurs when wave $S$ propagates through an anisotropic media, so that it can be divided into two polarized components that are perpendicular to each other, they are fast and slow components. Many research also have investigated a seismic anisotropy found on several earth layers; the earth crust layer and the layers exist between the mantle and core layers. On the upper layer, the characteristic that is usually found, is the anisotropic layer. The result of shear-wave splitting analysis gives direct information on a dynamic process, such as the mantle movement accumulated strain due to the previous deformation. The shearwave splitting analysis enables the researchers to 
study the anisotropic characteristic of the geological structure of the earth layers. The shear-wave splitting analyis in this study has used rotationcorrelation method for the purpose of analysing shear wave found in each monitoring station located in the northern Sumatra.

\section{EXPERIMENTAL METHOD}

The data were collected from four BMKG recording stations (IA Network) through GFZ network (Geo Forschungs Zentrum), shown in the Fig. 1. The data were taken from January 2012 to January 2014. The earthquake data used in this study were the earthquake events with the epicentre distance was about $85^{\circ}-140^{\circ}$. The determination of the epicentre distance was selected because it was an ideal event to analyse shear-wave splitting of the SKS/SKKS phase. The purpose of selection of the epicenter distance was to prevent the overlapping of the SKS/SKKS phase with the other phases as well to guarantee the seismic wave still has sufficient energy [4]. A total of earthquake events has been monitored by each station (only $37,5 \%$ of the data were used). Fig. 2 shows most of the events that can be monitored by the stations. The SKS/SKKS data were filtered using a bandpass filter (Buttherworth) between $0,02-0,1 \mathrm{~Hz}$. The filtering used to remove noise at the high and low frequencies so that it was expected to be able to increase the accuracy of the measurement.

The analysis of the shear-wave splitting was conducted by using Splitlab program [5], as provided in the Fig. 3. The polarization direction $(\phi)$ and delay time $(\delta \mathrm{t})$ were explored by grid search using Rotation-correlation method [3]. The seismogram rotation towards the coordinate system (LQT) was conducted on the rotation-correlation (RC) method, a rotation was divided into the three dimensional ray system (LQT) as follows:

$$
\left[\begin{array}{l}
L \\
Q \\
T
\end{array}\right]=\left[\begin{array}{ccc}
\cos \theta & -\sin \theta \sin \beta & -\sin \theta \cos \beta \\
\sin \beta & \cos \theta \sin \beta & \cos \theta \cos \beta \\
0 & -\cos \beta & \sin \beta
\end{array}\right]\left[\begin{array}{l}
Z \\
E \\
N
\end{array}\right]
$$

$\beta$ refers to the backazimuth angle (clockwise from north) and $\theta$ refers to the angle of incidence of the wave $\left(\theta=0^{\circ}\right.$ vertically incidence wave; $\theta=90^{\circ}$ for horizontally incidence wave (Plěsinger et al., 1986)). In this case, the positive (longitudinal) Lcomponent, which points along the ray path ( from the epicenter to the stations), and the Q-component are defined as positive components as they are pointing towards the earthquake. The T-component completes the right-handed coordinate system.

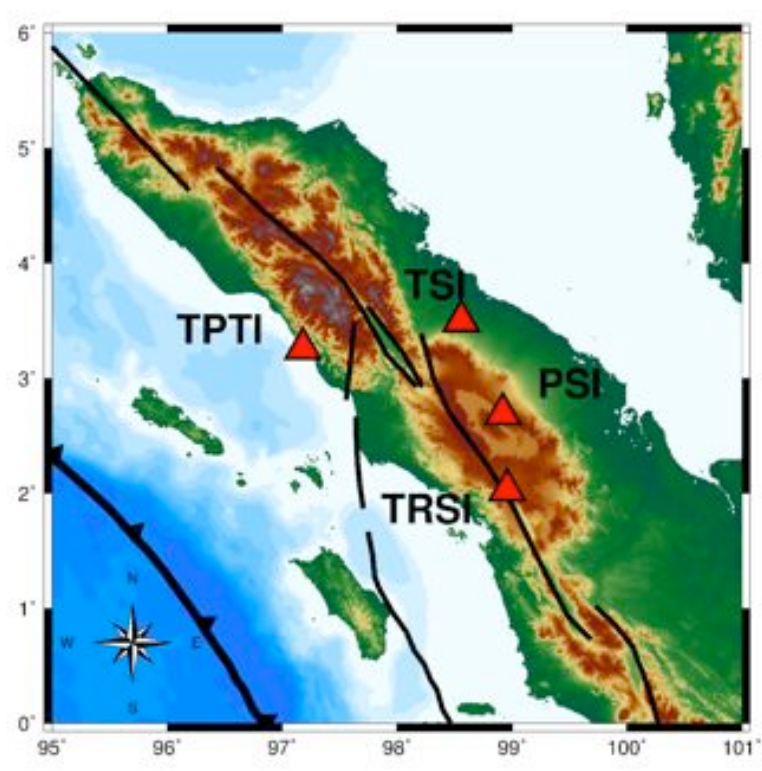

Fig. 1. A map of the observation location and the recording stations (it is shown by the red triangles)

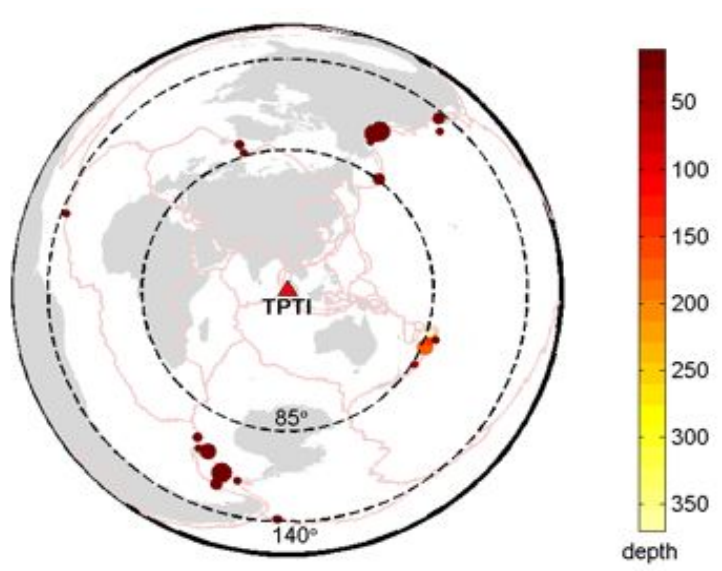

Fig. 2. The epicentral location of event used (it is marked by circle) relative towards the stations (it is marked by red triangle)

The angle of incident from each phase was calculated based on the function of ray path using matTaup toolbox, which was available in the SplitLab program. The RC method is functioning to investigate the polarization direction $(\phi)$ and delay time $(\delta \mathrm{t})$ by conducting cross-correlation between the component of Q and T (Fig. 3b) in each event at each recording station; to save the calculation result of the splitting parameter of the maximum value $\phi$ $\mathrm{RC}$ and $\delta \mathrm{t}-\mathrm{RC}$ resulted [3], [6]. The calculations of the polarization direction and delay time were conducted by calculating the differences of travel time and polarization angle taken from the fast and slow components when they reached the recording station. This technique can be visualised by looking for the combination of the splitting parameter $\phi$ and $\delta$ t, which maximizes the similarity in the form of non-normalised pulse of two corrected seismogram. 

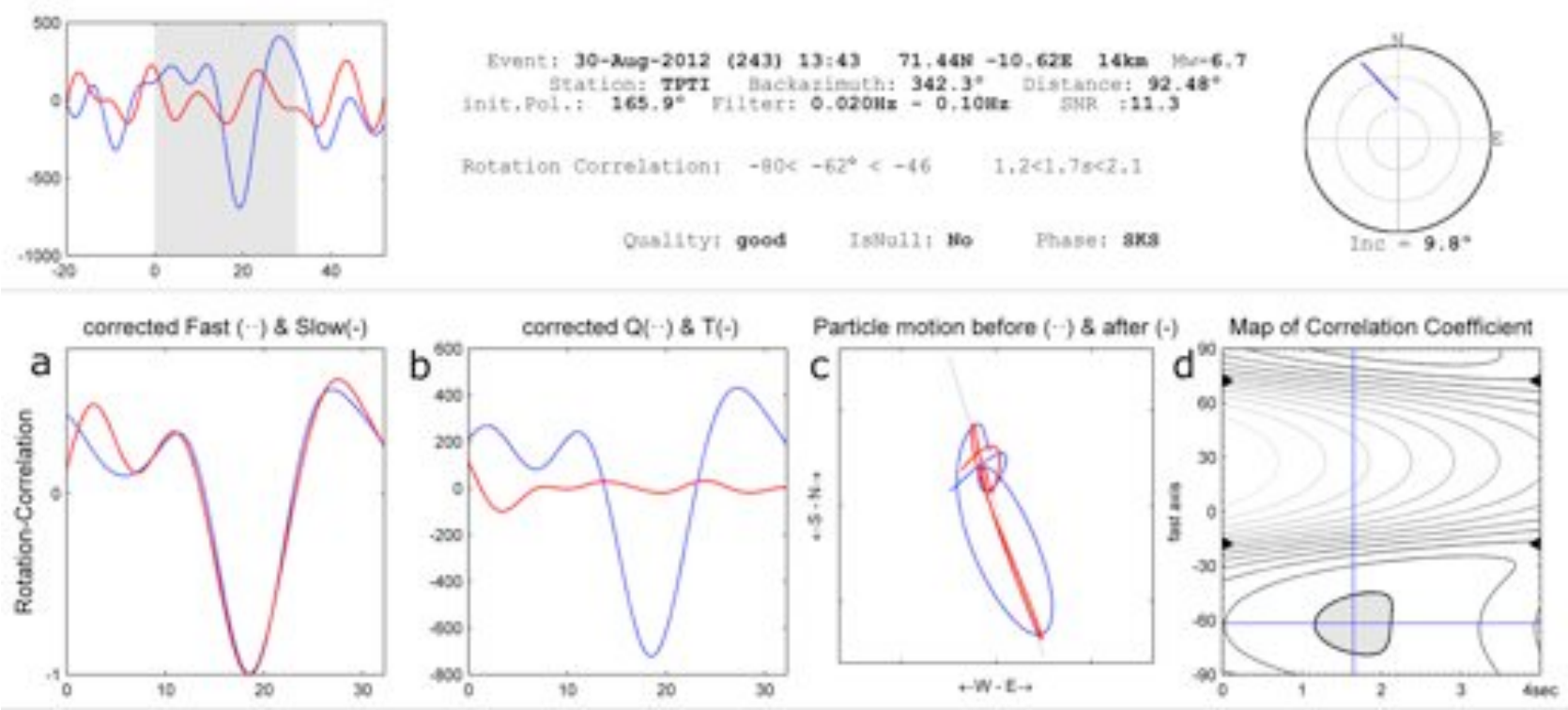

Fig. 3. An example of shear-wave splitting at TPTI stations obtained from Splitlab program. 3a refers to the result of the seismogram correction in the fast and slow components. $3 \mathrm{~b}$ refers to the result of the seismogram correction after conducting a rotation in the components $\mathrm{Q}$ and $\mathrm{T}$. $3 \mathrm{c}$ refers to the particle motions and $3 \mathrm{~d}$ refers to the determination of the coefficient-correlation of the calculation result.

The analysis quality is determined by several criteria; first is by a good signal to noise ratio (SNR) that can facilitate the identification phase; second, the linearization of the particle movement (Fig. 3c); third, the selection of back azimuth direction after it is corrected; and the last one is the validation of the calculation result using coefficient-correlation so that it can meet $95 \%$ of the confident error (Fig. 3d).

Based on the conditions, to determine the analytical quality, this study finally used three criteria (good, fair, and poor). The shear wavesplitting analysis was conducted at each station using the data of earthquake events, which had been already recorded. This study also selected the calculation results of earthquake events recorded at each stations. There were merely three criteria- good and fair- used in the further calculations. After selecting the results, this study in turn conducted a stacking process in order to obtain the polarisation angle value and the delay time at each station. The results of the shear-wave splitting analysis in each station was in turn sketched onto a topographic map using Generic Mapping Tool (GMT) program [7].

\section{RESULTS AND DISCUSSION}

Four broadband permanent stations that can be monitored, which is located in the northern Sumatra are PSI, TPTI, TSI and TRSI. The result of the shear-wave splitting analysis shows that two anisotropic layers exist in this region are the lower and upper layers anisotropy.

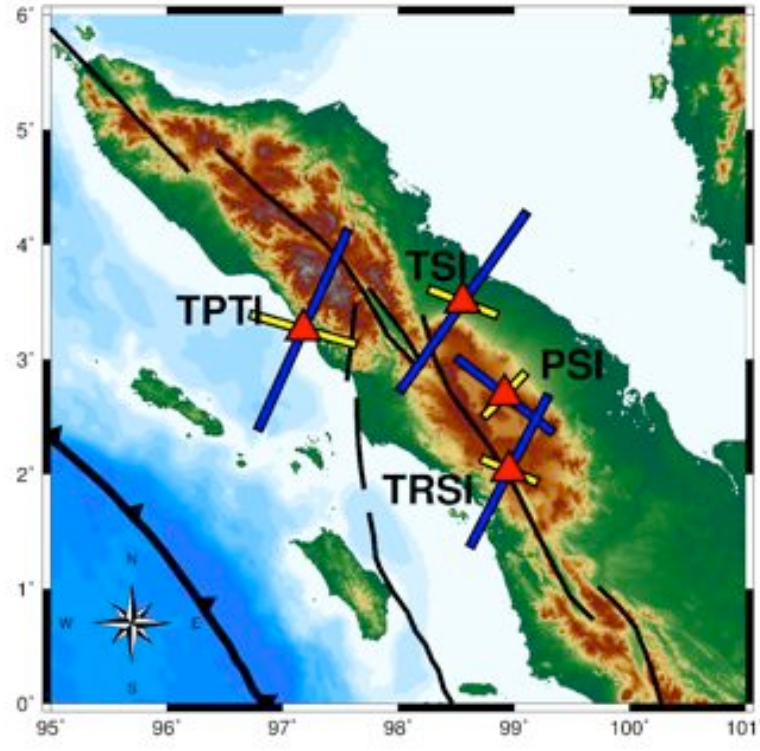

Fig. 4. A map of the shear-wave splitting measurement result in each monitoring station (red triangle) in Sumatra. The result of the measurement is represented as a thick line, the colour yellow represents the upper layer and the colour blue represents the lower layer. The black line represents the subduction zone, Sumatran faukt and Mentawai fault zones.

Anisotropy on the lower layer results in delay time about 1.4-1.8 $\mathrm{s}$ with the same dominant polarization direction, that is northeast-southwest (NE-SW) and it is perpendicular to trench in Sumatran forearc, as shown in the Fig. 4.

The study of shear-wave splitting that have been conducted globally by [8] shows that the result of the shear-wave splitting analysis dominated by the polarization direction which is parallel to trench with some exceptions (Cascadia [9] and south 
central Chile [10]). The result of the shear-wave splitting analysis in the northern Sumatra is usually perpendicular to trench. This result does not match the shear wave splitting observation conducted in global trench [8]. However, this result matches the previous studies [1], [11] show that the result of shear-wave splitting monitored in the northern Sumatra has the polarization direction which is perpendicular to trench. A previous study [12] describes that the result of delay time analysis $(\delta \mathrm{t})$ with the range of value is 1.0-2.4 $\mathrm{s}$ has shown the existence of main anisotropic resources on the upper mantle caused by mantle flow activity or subduction zone. It indicates the existence of anistropic layers on the upper mantle, which is assumed as steep subduction plate beneath the northern Sumatra.

The second anisotropic layer shows the delay time between 0.5-0.9 $\mathrm{s}$ with the same dominant polarization direction, that is northwest-southeast (NW-SE) or it is parallel to trench (Fig. 4). It can be predicted that there is a more shallow anisotropic layer than subduction plate. This layer is assumed as Sumatra fault zones located in the northen Sumatra. The result is in line with the observation result of fault zone in Sumatra, showing that there 19 fault segments which split Sumatra island, they are Tripa and Renun faults, found in the northern Sumatra [13].

The calculation results show the difference of the polarization direction between PSI station and the three other stations (Fig. 4). It is assumed that the difference caused by the existence of a different anisotropic zone compared to any other region. Based on the geological structure in the region, the PSI station is located around Toba lake. Toba lake is assumed as a caldera from supervolcano activity. The previous study [14] shows the existence of molten rocks which moves upwards, released from subduction plate due to the transition phase beneath the Toba caldera. This is assumed as a factor that makes the analysis result of the PSI station is rather different and more complex than the others, in which it occurs due to the effect of the layer anomaly beneath Toba caldera.

\section{CONCLUSION}

The result of the shear-wave splitting analysis in the northern Sumatra shows the presence of two anisotropic layers; those are anisotropic layer of the Sumatran fault on the upper part and anisotropic layer of the subduction plate beneath the lower layer. There is a difference of the calculation results between PSI station and the three other stations, which is assumed that it occurs due to the complex layer beneath the Toba caldera. Any further study is needed to investigate the effect of the Toba caldera in tectonic structure in the northern Sumatra.

\section{ACKNOWLEDGMENT}

The main author greatly acknowledges the Directorate General of the Higher Education of the Republic of Indonesia for supporting him through DIKTI Graduate Scholarship grant. All figures were generated by using the open-source Generic Mapping Tools (GMT) software [7].

\section{REFERENCES}

[1] J. O. S. Hammond, J. Wookey, S. Kaneshima, H. Inoue, T. Yamashina, and P. Harjadi, "Systematic variation in anisotropy beneath the mantle wedge in the Java-Sumatra subduction system from shear-wave splitting," Phys. Earth Planet. Inter., vol. 178, no. 3-4, pp. 189-201, Feb. 2010.

[2] L. P. Vinnik, V. Farra, and B. Romanowicz, "Azimuthal anisotropy in the earth from observations of SKS at GEOSCOPE and NARS broadband stations," Bull. Seismol. Soc. Am., vol. 79, no. 5, pp. 1542-1558, Oct. 1989.

[3] J. R. Bowman and M. Ando, "Shear-wave splitting in the upper-mantle wedge above the Tonga subduction zone," Geophys. J. R. Astron. Soc., vol. 88, no. 1, pp. 25-41, Jan. 1987.

[4] P. G. Silver and W. W. Chan, "Shear wave splitting and subcontinental mantle deformation," J. Geophys. Res. Solid Earth, vol. 96, no. B10, pp. 16429-16454, Sep. 1991.

[5] A. Wüstefeld, G. Bokelmann, C. Zaroli, and G. Barruol, "SplitLab: A shear-wave splitting environment in Matlab," Comput. Geosci., vol. 34, no. 5, pp. 515-528, May 2008.

[6] Y. Fukao, "Evidence from core-reflected shear waves for anisotropy in the Earth's mantle," Nature, vol. 309, no. 5970, pp. 695-698, Jun. 1984.

[7] P. Wessel and W. H. F. Smith, "Free software helps map and display data," Eos Trans. Am. Geophys. Union, vol. 72, no. 41, pp. 441-446, Oct. 1991.

[8] M. D. Long and P. G. Silver, "The Subduction Zone Flow Field from Seismic Anisotropy: A Global View," Science, vol. 319, no. 5861, pp. 315-318, Jan. 2008. 
[9] C. A. Currie, J. F. Cassidy, R. D. Hyndman, and M. G. Bostock, "Shear wave anisotropy beneath the Cascadia subduction zone and western North American craton," Geophys. J. Int., vol. 157, no. 1, pp. 341-353, Apr. 2004.

[10] S. P. Hicks, S. E. J. Nippress, and A. Rietbrock, "Sub-slab mantle anisotropy beneath south-central Chile," Earth Planet. Sci. Lett., vol. 357-358, pp. 203-213, Dec. 2012.

[11] R. Collings, A. Rietbrock, D. Lange, F. Tilmann, S. Nippress, and D. Natawidjaja, "Seismic anisotropy in the Sumatra subduction zone," J. Geophys. Res. Solid Earth, vol. 118, no. 10, pp. 5372-5390, Oct. 2013.
[12] H. Kuo-Chen, F. T. Wu, D. Okaya, B.-S. Huang, and W.-T. Liang, "SKS/SKKS splitting and Taiwan orogeny," Geophys. Res. Lett., vol. 36, no. 12, p. L12303, Jun. 2009.

[13] K. Sieh and D. Natawidjaja, "Neotectonics of the Sumatran fault, Indonesia," J. Geophys. Res., vol. 105, no. B12, p. 28295, 2000.

[14] I. Koulakov, T. Yudistira, B.-G. Luehr, and Wandono, "P, $\mathrm{S}$ velocity and VP/VS ratio beneath the Toba caldera complex (Northern Sumatra) from local earthquake tomography," Geophys. J. Int., vol. 177, no. 3, pp. 11211139, Jun. 2009. 